\title{
Investing in Communities: Evaluating the Added Value of Community Mobilization on HIV Prevention Outcomes Among FSWs in India
}

\author{
Anne Sebert Kuhlmann • Christine Galavotti • \\ Philip Hastings · Pradeep Narayanan · \\ Niranjan Saggurti
}

Published online: 16 October 2013

(C) The Author(s) 2013. This article is published with open access at Springerlink.com

\begin{abstract}
Community mobilization often requires greater time and resource investments than typical interventions, yet few evaluations exist to justify these investments. We evaluated the added benefit of community mobilization on HIV prevention outcomes among female sex workers (FSWs) using a composite measure of volunteer participation in program committees by FSWs. After adjusting for treatment propensity, we used multilevel structural equation modeling (MSEM) to test our program theory. We hypothesized that stronger community mobilization would be associated with increased levels of consistent condom use and with increased levels of perceived fairness, mediated by psychosocial processes. Community mobilization had an indirect effect on consistent condom use mediated through social cohesion and an indirect effect on perceived fairness mediated by collective efficacy. Our results suggest higher levels of community mobilization help improve condom use and reduce perceived discrimination beyond the effects of the core HIV intervention program. We recommend further testing of this model.
\end{abstract}

\author{
A. S. Kuhlmann ( $₫)$ \\ Washington University in St. Louis, One Brookings Drive, St. \\ Louis, MO 63130, USA \\ e-mail: Asebertk@wustl.edu \\ C. Galavotti ( () \\ CARE USA, 151 Ellis Street, Atlanta, GA 30303, USA \\ e-mail: cgalavotti@care.org \\ P. Hastings \\ Far Harbor LLC, Austin, TX, USA \\ P. Narayanan \\ Praxis Institute for Participatory Practices, New Delhi, India \\ N. Saggurti \\ Population Council, New Delhi, India
}

Resumen Movilización de comunidad requiere más tiempo e inversión de recursos que una típica intervención, pero muy pocas evaluaciones existen para justificar estas inversiones. Se evaluó el beneficio de movilización de comunidad en la prevención de VIH en sexoservidoras usando un indicador compuesto de participación de voluntarios en comités de programa por sexoservidoras. Después de ajustar por propensión de tratamiento, se usó una ecuación de múltiple niveles estructural para probar nuestra teoría de programa. Nuestra hipótesis es que una movilización de comunidad más fuerte estuviese asociada con un nivel aumentado de uso de condones consistente con niveles aumentados de imparcialidad percibida, mediada por procesos psicosociales. Movilización de comunidad tuvo un efecto indirecto en el uso de condones consistente mediado por cohesión social y un efecto indirecto en la percibida imparcial mediado por eficacia colectiva. Nuestros resultados sugieren que niveles elevados de movilización de comunidad ayudan a mejorar uso de condones y reducir discriminación percibida más allá de los efectos de la intervención del programa de VIH. Recomendamos pruebas adicionales de este modelo.

Keywords Community participation - Community mobilization · HIV prevention · Female sex workers . Evaluation methodology

\section{Introduction}

Although most HIV prevention program implementers recognize that community participation and mobilization is important to program success, community mobilization as an intervention strategy usually necessitates greater and longer term investments of financial and human resources 
than more traditional HIV prevention interventions. While more traditional, targeted HIV prevention interventions such as peer education and outreach with condom distribution have shown positive impacts on HIV prevention behaviors among individuals of high-risk groups [1-3], the impacts of community mobilization have been less well documented. Community mobilization seeks to engage participants in a way that increasingly allows them to make decisions and shape their own lives [4]. Spurring and supporting this deepening engagement often requires significant human resources and time investments to facilitate development of decision-making, leadership, and management skills in marginalized populations. In an era of increasingly limited resources, funders and policy makers are particularly keen to see evidence that community mobilization produces substantially better HIV prevention outcomes or additional benefits to justify these larger investments. And, though there is some evidence that community mobilization improves HIV prevention outcomes [5-7], how community mobilization works to produce these outcomes remains virtually unexplored.

Understanding how community mobilization may contribute to program success is complicated by several factors. First, there is no common definition of community mobilization-interventions range from community education and sensitization to community-led structural interventions-and effects of such a wide range of interventions are likely to vary just as widely. Further, few authors have laid out a conceptual model or program theory that explains how community participation and mobilization is expected to lead to specific outcomes: what is the mechanism of effect? Thus, we lack consensus on what intervention activities constitute a community mobilization intervention, what a "mobilized community" looks like, and how that mobilization is expected to result in the desired program outcomes. Evaluation is further hampered by the fact that community mobilization is an inherently complex and dynamic process that occurs over time, evolving in ways that may be heavily dependent on the community and the context in which it is undertaken.

Nevertheless, community mobilization continues to be an important component of many public health interventions, and has been shown to have an effect on a variety of sexual, reproductive, maternal, and child health outcomes. Researchers have found evidence of a significant, positive impact of community mobilization on reducing child stunting in Bangladesh [8], reducing neonatal mortality rates in Nepal [9], India [10], and Malawi [11], and some evidence for increasing birth planning and emergency transportation in Bangladesh [12]. Thus, knowledge gained about how community mobilization works may be applicable to a variety of sexual, reproductive, maternal, and child health areas.

Avahan, the India AIDS Initiative funded by the Bill and Melinda Gates Foundation, works with a number of highrisk groups in the six Indian states with the highest HIV prevalence. Avahan funds one or two state lead partners (SLPs) in each state who then fund and work with hundreds of local non-governmental organizations (NGOs) to implement the intervention [13]. Avahan's scale of reaching nearly 200,000 female sex workers (FSWs) in 83 districts across 6 states with a combined population of 300 million [13] along with its work with a large range of highrisk groups (e.g., FSWs, male clients of sex workers, truck drivers) has been unparalleled in community mobilization and HIV prevention. Thus, Avahan provides a unique opportunity to evaluate the potential added value of a community mobilization intervention on HIV prevention outcomes as well as to examine the impact of community mobilization on additional outcomes that would not be expected from more traditional, targeted intervention strategies.

Avahan planners carefully laid out a multi-level population impact assessment early on in the program [14]. For a variety of reasons, however, evaluating the community mobilization component was not included as part of this initial impact assessment plan. Early results from the monitoring data and staff perceptions nevertheless suggested that the community mobilization intervention activities played a critical role in Avahan: community members (i.e., members of the high-risk group targeted by the intervention, in this case FSWs) helped to map highrisk populations in the districts, advised on key program decisions like the location of health clinics and drop-in centers, and worked as peer educators contacting over $70 \%$ of the high-risk population in intervention districts on a monthly basis [13, 15-17].

The challenge, therefore, was how to design and implement an evaluation of Avahan's community mobilization efforts after initial program implementation had already begun. We chose to use theory-based evaluation [18]. We articulated a program theory to describe how Avahan's intervention spurs and supports the community mobilization process and how that process leads to enhanced HIV prevention outcomes and additional benefits, and then developed a phased evaluation plan to test this program theory (see Galavotti et al. [4] for further information on the program theory). In this paper, we present results from the first phase of the evaluation assessing the added value of community mobilization on HIV prevention outcomes among FSWs in Andhra Pradesh, India. 


\section{Methods}

The Model and Hypotheses

The primary goal of Avahan is to reduce HIV infection by promoting risk reduction behaviors and supporting an enabling environment among high risk groups. Across Avahan, a common core of targeted intervention activities are implemented including drop-in centers, peer outreach, condom distribution, crisis response and services for sexually transmitted infections (STIs). The community mobilization component of Avahan consists of the work to engage sex workers in program activities, from encouraging participation in initial community mapping and outreach and membership in project committees, to facilitating their management of crisis response teams and their taking leadership roles in formal and informal community based organizations; the greater the participation, engagement and ownership of the intervention by the FSWs, the more "mobilized" the community. The goal of this community participation is to mobilize the community of sex workers so that they can increasingly make decisions, influence their environment, and shape their lives in ways that support their health and well-being, including prevention of HIV infection.

Our program theory describes how this participation sets in motion a number of causal processes (mediators) through which the intervention ultimately leads to better program outcomes. These mediating variables reflect the expanding interpersonal, social and political space that sex workers inhabit as mobilization unfolds. The process begins when sex workers claim their identity as sex workers and begin to see themselves as part of a community [19]. This identification is characterized by increased self-confidence, individual agency (e.g., I can refuse a client when tired), and self-efficacy. As social cohesion and connectedness grow, sex workers begin to understand that they are part of a group that faces common concerns, experiences and needs [20]. This collectivization is characterized by a strong sense of collective identity, collective efficacy, agency and action (e.g., FSWs can work together to achieve goals, stand up for each other), and social cohesion (e.g., trust, reciprocity, belongingness). (Please see Galavotti et al. [4] for a more detailed discussion of the program theory and how the Avahan intervention spurs and supports the community mobilization process.)

Based on our program theory, we constructed a model (see Fig. 1) to test the hypothesis that higher levels of community mobilization would result in increased identification and collectivization which in turn would lead to more positive HIV prevention outcomes. This model does not represent the full program theory as we could only test those variables in the model for which we could collect valid data.
Evaluation Design

Our evaluation focused on FSWs in the state of Andhra Pradesh within a district served by one of Avahan's implementing partners. ${ }^{1}$ Conducting the evaluation in areas where a single state lead implementing partner (SLP) was delivering the intervention helped minimize intervention variation due to implementation style of the SLP; it also minimized contextual effects that might arise from geographic and cultural differences across states in India.

To achieve adequate sample size, we sampled 104 geographic clusters within the district and then measured strength of the treatment (i.e. level of community mobilization) at the cluster level. These clusters were small geographic units under the responsibility of one outreach worker (ORW) who served $\sim 250 \mathrm{FSW}$. This unit then became the area in which we measured "strength of community mobilization", as well as our primary sampling unit for the survey of sex workers. Although all 104 clusters implemented the same core program activities, we anticipated that the level of community mobilization, i.e. volunteer participation and engagement of FSWs in those activities, would vary.

Next, we defined our measure of treatment strength: level of community mobilization in the cluster. Previous researchers have shown positive relationships between selfreported exposure to the program (as a proxy for community mobilization) and both psychosocial and behavioral outcomes [21, 22]. Most recently, a study of Avahan in Karnataka showed a positive effect of self-reported exposure to the community mobilization intervention on condom use and uptake of HIV/STI services outcomes [23]. However, self-reported measures of treatment exposure are subject to recall bias, as well as selection bias, since those who participate may be different from those who do not. Further, since community mobilization is a communitylevel, not an individual-level, intervention, it makes sense to measure treatment strength at the community rather than the individual level.

To create an unbiased measure of treatment strength at the community level, we needed an independent measure of the level of community mobilization in the cluster. Although extensive program monitoring data were available to confirm implementation of intervention activities, community mobilization is not the activities themselves but rather the level of participation, engagement and ownership of the community in those activities. Identifying reliable measures of "mobilization" that were collected through routine program monitoring data proved impossible.

Therefore, we collected data from the ORWs responsible for the defined clusters and validated these data by

\footnotetext{
${ }^{1}$ HIV/AIDS Alliance was the state lead implementing partner.
} 


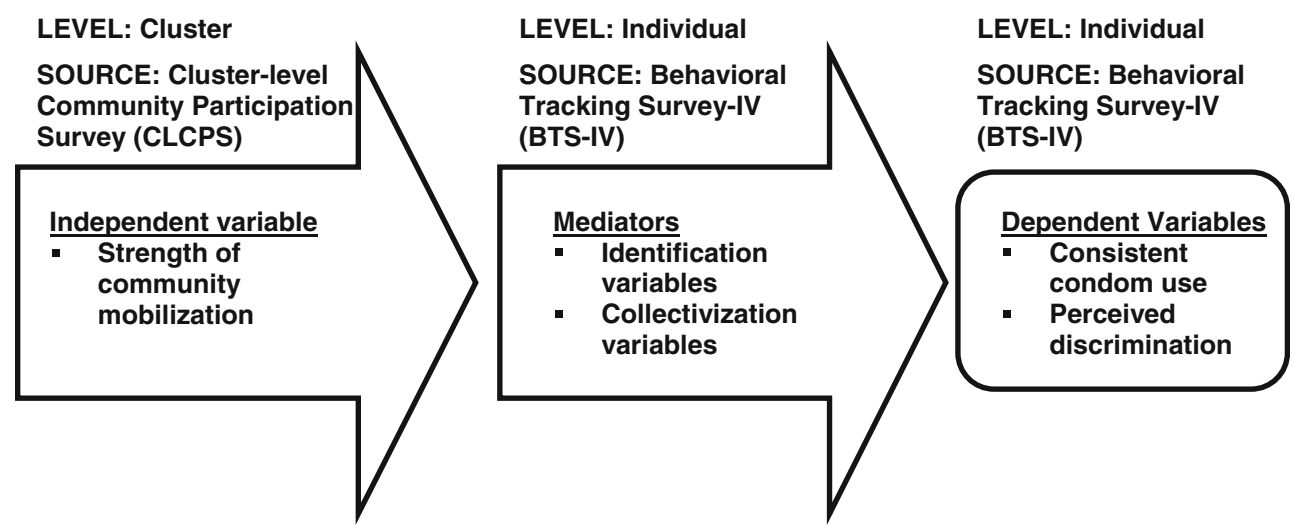

Fig. 1 Model for evaluation of community mobilization: level and source of data for key constructs

reviewing program records (described more in "Data Sources and Collection" section). Our measure of the strength of the intervention assessed the level of participation in specific program committees by volunteer FSWs (vs. paid staff or paid peers) in a given geographic cluster. Level of participation is an indicator of interest and involvement, and volunteer participation suggests an even greater level of commitment and ownership. We were thus able to characterize clusters in terms of the strength of the treatment: community mobilization.

Still, we faced further challenges in the design of the evaluation. Avahan was designed to be implemented at scale (saturating districts with the intervention) and no control sites were planned. Therefore, our only option was to investigate whether the intervention strength would exhibit a dose-response relationship to our outcomes of interest among the "treated" clusters. A vulnerability of this approach is that selection bias can arise among clusters, since individuals were not randomly assigned to levels of the intervention-treatment strength in a cluster could only be observed, not controlled.

The classic strategy for minimizing selection bias is to employ a randomized controlled design, which is not typically available for field interventions. To address this issue, we used a propensity score method to reweight the original sample such that the pre-intervention confounding variables were unrelated to level of treatment in the reweighted sample. Propensity score methods can be effective in minimizing selection bias by creating a weighted pseudo-sample (conditioned on the observed confounders) which somewhat approximates a randomized design. The details of this adjustment are further described in the "Analysis Process" section.

We could not use data from previous surveys in the district as a baseline for our behavioral outcomes and mediators since those data were collected using a different sampling frame. Our outcome measures-consistent condom use with clients and perceived discrimination-and our mediating variables were therefore collected via an independent survey of FSWs in the same 104 geographic clusters.

This cross-sectional, dose-response design, using an independent measure of strength of treatment at the cluster level, allowed us to explore whether (high) community mobilization leads to improved program outcomes above and beyond what would be expected from the core Avahan HIV interventions (no/low mobilization). Using multi-level structural equation modeling (MSEM) coupled with propensity score reweighting to adjust for selection bias, our approach attempted to simulate a randomized doseresponse trial to estimate non-biased treatment effects.

\section{Data Sources and Collection}

\section{Cluster-Level Community Participation Survey (CLCPS)}

Because self-reported measures of exposure to, and participation in, an intervention program suffer from problems of recall and social desirability biases that tend to conflate self-reported program exposure with positive outcomes (especially when such data are collected within the same survey), we measured strength of community mobilization through the CLCPS, which provided a profile of community participation within the clusters. ORWs in 104 clusters were interviewed using a series of questions to measure community participation in program implementation, program management, crisis response, decision-making, and program activities. Data ranged from information about proportion of community members planning, implementing and overseeing program activities, to governance processes, leadership and ownership. These variables served as the basis for a composite intervention strength variable characterized by the level of community participation in each cluster. We validated the information provided by the ORWs through structured interviews with peer educators and ORWs responsible for the cluster and detailed reviews 
of organizational documents such as meeting minutes, micro-planning documents detailing monthly outreach contacts, organizational by-laws, and annual reports. The data collection tool and process for the CLCPS were based on a detailed participatory monitoring tool being used in a select number of Avahan districts [24].

\section{Behavioral Tracking Survey (BTS-IV)}

In the same sample of 104 clusters where the CLCPS was conducted, individual FSWs were randomly sampled for participation in a BTS-IV using a two-stage sampling procedure. In the first stage, a fixed number of hotspots within each cluster were selected via the proportion to population size (PPS) procedure. In the second stage, we selected participants using either conventional cluster sampling from non-public places (e.g., brothels) or timelocation cluster sampling from public places (e.g., streets, parks, highways). We collected information on the number of FSWs per hotspot and the times when they gathered for sex work in order to weight the sample. More detail on the sampling process for this survey has been published elsewhere [25]. A total of 1,986 FSWs participated in the BTSIV, of 2,389 sampled, for an unweighted response rate of $83.1 \%$.

The BTS survey has been used across Avahan and modified several times over the last few years. Previous rounds of the BTS in Andhra Pradesh were conducted using a different sampling frame and thus not useful for purposes of this evaluation; however, we did modify and use the tool for this survey. The BTS measures demographics, socioeconomic situation, sex work history, condom use, perceptions of sex worker solidarity and efficacy, participation in FSW organizations and events, and selfreported exposure to the intervention. For the BTS-IV, we added a number of variables specific to this evaluation, including time since first exposed to the Avahan intervention, self-efficacy scales for condom use and for service utilization, contraceptive use, a social cohesion scale validated for use with sex workers [26], and a validated depression measure [27].

\section{Ethical Considerations}

The overall study design and questionnaires were reviewed and approved by the institutional review boards of Family Health International and the Karnataka Health Promotion Trust. Oral consent was obtained from all respondents prior to participation in the interview, and steps were taken to ensure their confidentiality. For ethical reasons, only those FSWs who were at least 18 years of age were interviewed. No names or addresses were recorded on the questionnaires. Participants were not provided any compensation for their time in the study but were referred to local project services run by the SLP in the district.

\section{Measures}

\section{Treatment Variable}

A high rate of community (FSW) volunteers serving on intervention planning, implementation and oversight committees is a critical indicator of community mobilization. Thus, strength of community mobilization was calculated as the average percentage of volunteer FSWs participating on seven program-related committees within the cluster, as compared to the total committee membership (i.e. the ratio of volunteers to volunteers plus paid staff).

\section{Dependent Variables}

We measured HIV prevention as consistency of condom use with both occasional and regular clients by FSWs in the cluster. We also tested a second outcome variable, perceived discrimination in a variety of public places (reverse coded as perceived fairness), as a measure of an enabling environment conducive for HIV prevention.

\section{Mediating Variables}

Indicators for identification included claiming identity as a sex worker, individual agency to refuse clients when tired and to make decisions about one's own life, self-efficacy for condom use with clients, self-efficacy for service utilization, self-confidence in obtaining condoms and in giving advice, and mental health. Indicators for collectivization included collective identity of attending events where one could be identified as a FSW, collective efficacy for FSWs working together to solve problems and for FSWs working together to achieve goals, collective agency for standing up for those in need, collective action of FSWs working together to demand entitlements, and social cohesion among FSWs in the cluster. Table 1 provides greater detail on our variables and their sources.

\section{Analysis Process}

\section{Treatment Propensity Adjustment}

Due to the potential bias associated with nonrandom selection of FSWs into clusters with varying levels of community mobilization, we employed a propensity score methodology to reweight the data. Studies have shown that propensity methods can remove up to $90 \%$ of the bias resulting from observable confounders [28, 29]. We therefore identified 18 confounders that might influence 
Table 1 Type, description, and source of variables (weighted means and percentages)

\begin{tabular}{|c|c|c|c|c|c|c|c|c|}
\hline Variable & Description & Items $(\propto+)$ & $N$ & Min & Max & Mean & SE & Source \\
\hline \multicolumn{9}{|l|}{ Treatment variable } \\
\hline $\begin{array}{l}\text { Strength of community } \\
\text { mobilization }\end{array}$ & $\begin{array}{l}\text { Average } \% \text { of unpaid FSWs serving on seven } \\
\text { committees in cluster }\end{array}$ & $1(-)$ & 104 & 0.17 & 0.73 & 0.45 & 0.01 & CLCPS \\
\hline \multicolumn{9}{|l|}{ Identification mediators } \\
\hline Claim identity & Willingness to self-identify as a FSW & $2(0.62)$ & 1,943 & 1.0 & 4.0 & 2.90 & 0.04 & BTS-IV \\
\hline Self-confidence 1 & Confidence in obtaining condoms & $1(-)$ & 1,943 & 1.0 & 4.0 & 2.47 & 0.07 & BTS-IV \\
\hline Self-confidence 2 & Confidence in giving advice/opinions & $2(0.66)$ & 1,943 & 1.0 & 4.0 & 2.59 & 0.04 & BTS-IV \\
\hline Self-efficacy 1 & Self-efficacy for condom use with clients & $3(0.77)$ & 1,943 & 1.0 & 4.0 & 2.71 & 0.03 & BTS-IV \\
\hline Self-efficacy $3^{\mathrm{a}}$ & Self-efficacy for service utilization & $2(0.83)$ & 1,943 & 1.0 & 4.0 & 2.61 & 0.05 & BTS-IV \\
\hline Individual agency 1 & Turning away clients if tired & $1(-)$ & 1,940 & 0.0 & 3.0 & 0.99 & 0.06 & BTS-IV \\
\hline Individual agency 2 & Autonomy for personal actions & $7(0.87)$ & 1,943 & 0.0 & 1.0 & 0.67 & 0.02 & BTS-IV \\
\hline Mental health & Mental health (depression reverse coded) & $2(0.88)$ & 1,943 & 1.0 & 4.0 & 2.98 & 0.07 & BTS-IV \\
\hline \multicolumn{9}{|l|}{ Collectivization mediators } \\
\hline Collective identity & $\begin{array}{l}\text { Attended a public event in last } 6 \text { months } \\
\text { where could be identified as a FSW }\end{array}$ & $1(-)$ & 1,943 & 0.0 & 1.0 & 0.67 & 0.03 & BTS-IV \\
\hline Collective efficacy 1 & $\begin{array}{l}\text { FSWs would work together if problem } \\
\text { affected the group }\end{array}$ & $1(-)$ & 1,943 & 1.0 & 4.0 & 2.56 & 0.07 & BTS-IV \\
\hline Collective efficacy 2 & FSWs work well together for specific goals & $4(0.75)$ & 1,942 & 0.0 & 3.0 & 1.96 & 0.03 & BTS-IV \\
\hline Collective agency & Negotiated or stood up for FSW in need & $4(0.76)$ & 1,943 & 0.0 & 1.0 & 0.38 & 0.02 & BTS-IV \\
\hline Collective action & FSWs come together to demand entitlements & $7(0.80)$ & 1,943 & 0.0 & 1.0 & 0.15 & 0.02 & BTS-IV \\
\hline Social cohesion & Sharing issues, relying on fellow FSWs & $12(0.69)$ & 1,943 & 1.3 & 4.0 & 3.00 & 0.04 & BTS-IV \\
\hline \multicolumn{9}{|l|}{ Outcome variables } \\
\hline $\begin{array}{l}\text { Condom use with } \\
\text { clients, continuous }\end{array}$ & $\begin{array}{l}\text { Mean frequency of condom use with regular } \\
\text { clients and occasional clients }(1=\text { never to } \\
4=\text { always })\end{array}$ & $2(0.77)$ & 1,943 & 1.0 & 4.0 & 3.51 & 0.03 & BTS-IV \\
\hline \multirow{3}{*}{$\begin{array}{l}\text { Condom use with } \\
\text { clients, categorical }\end{array}$} & Low & & 349 & & & $20.46 \%$ & 1.76 & BTS-IV \\
\hline & Medium & & 409 & & & $18.59 \%$ & 1.73 & \\
\hline & High & & 1,185 & & & $60.95 \%$ & 2.43 & \\
\hline $\begin{array}{l}\text { Perceived } \\
\text { discrimination }\end{array}$ & $\begin{array}{l}\text { FSWs perception of discrimination in public } \\
\text { places, such as hospitals, bank, and post } \\
\text { offices (reverse coded into perceived } \\
\text { fairness) }\end{array}$ & $4(0.80)$ & 1,943 & 1.0 & 4.0 & 2.66 & 0.04 & BTS-IV \\
\hline \multicolumn{9}{|c|}{ Cluster-level confounder variables } \\
\hline Length of intervention & Months since intervention started in the cluster & $1(-)$ & 104 & 25.0 & 111.0 & 54.50 & 2.09 & CLCPS \\
\hline FSW density & $\begin{array}{l}\text { Estimated density of FSWs per kilometer in } \\
\text { cluster }\end{array}$ & $1(-)$ & 104 & 10.0 & 243.0 & 64.74 & 4.27 & CLCPS \\
\hline
\end{tabular}

${ }^{a}$ Indicates variable only used in models of perceived discrimination

+ Full sample $(n=1,986)$ unweighted Cronbach's alpha

selection into clusters and the outcomes of interest. Confounding variables were selected a priori following guidelines provided by Yanovitzky et al. [30]. Before data collection, researchers asked subject matter experts familiar with the target population and prior empirical evidence to identify those variables that might influence both an individual's selection into the program cluster as well as an individual's outcomes. A final set of demographic characteristics expected to be stable before program intervention and unlikely to be influenced by the intervention were included in the survey during data collection. This set of variables was then used during propensity modeling to estimate an individual's probability of selection into treatment quintile. The variables included demographics 
such as age, marital status, education, income, living and work situations, and number of children.

The confounders were used in separate and combined multinomial logistic regressions to predict treatment quintile as the dependent variable (clusters were ordered by strength of community mobilization to form these quintiles). The inverse of an individual's predicted probability of being in a treatment quintile (given the full set of confounders) was used to reweight the sample. The sample was trimmed to remove 43 observations with very low probabilities $(<5 \%)$ so these cases would not have outsize influence on model results [31]. The multinomial logistic model was then retested with the propensity-weighted data. None of the confounders were significantly related to treatment after reweighting, suggesting that the propensity adjustment successfully removed the effect of these variables as significant sources of bias in the analyses (see Table 2).

\section{MSEM}

Our model hypothesized that stronger community mobilization would influence psychosocial variables (indicative of identification and collectivization), and that changes in these mediators would be associated with positive HIVprevention outcomes. The two cluster-level outcomes were: (1) degree of consistent condom use with clients and (2) level of perceived discrimination. Since the strength of community mobilization (measured by the percentage of volunteer FSW participation on committees) was implemented and measured at the cluster level, our analysis necessarily focuses on cluster-level impacts. Stated another way, strength of community mobilization could not have effects at the individual (within-cluster) level since all members of a cluster are assigned the same community mobilization strength value. During the multi-level modeling process, individually measured variables are separated into within- and between-level variance components; the influences of community mobilization strength are evaluated on these between-level components (analogous to mean rates by cluster).

Models also included two cluster-level covariates, the geographic "density" of FSWs in each cluster (per square kilometer) and the time since the cluster intervention began. In this way we tried to ensure that the estimated effect of increased community mobilization was not conflated with the age of the program or the relative density of the target population.

Given the set of psychosocial scales, modeling proceeded in steps to keep the number of estimated parameters from exceeding the total number of clusters $(n=104)$. First, the identification variables (scales for claiming identity, individual agency, self-efficacy, self-confidence,
Table 2 Significance of individual-level confounders from multiple regression predicting participation, before and after propensity adjustment, BTS-IV (original sample $n=1,986$; trimmed sample $n=1,943$ )

\begin{tabular}{|c|c|c|c|c|c|}
\hline \multirow[b]{2}{*}{ Variable } & \multirow[b]{2}{*}{ df } & \multicolumn{2}{|c|}{$\begin{array}{l}\text { Original } \\
\text { Sample-- } \\
\text { Participation \% } \\
\text { regressed on } \\
\text { confounders }\end{array}$} & \multicolumn{2}{|c|}{$\begin{array}{l}\text { Propensity- } \\
\text { Adjusted, } \\
\text { Scaled, } \\
\text { Trimmed } \\
\text { Sample }\end{array}$} \\
\hline & & $\begin{array}{l}\text { Wald } \\
F \text { value }\end{array}$ & $p$ & $\begin{array}{l}\text { Wald } \\
F \text { value }\end{array}$ & $p$ \\
\hline Age in years & 1 & 4.76 & $0.03 *$ & 0.54 & 0.46 \\
\hline Age at first sex & 1 & 5.48 & $0.02 *$ & 0.77 & 0.38 \\
\hline Years of education & 1 & 4.93 & $0.03 *$ & 0.49 & 0.48 \\
\hline Years in sex work & 1 & 6.26 & $0.01 *$ & 0.64 & 0.43 \\
\hline Marital status & 3 & 1.80 & 0.15 & 0.33 & 0.81 \\
\hline Current living situation & 3 & 1.29 & 0.28 & 0.27 & 0.85 \\
\hline Environment for sex work & 2 & 0.29 & 0.75 & 0.15 & 0.86 \\
\hline $\begin{array}{l}\text { Frequency of travel for sex } \\
\text { work }\end{array}$ & 2 & 2.48 & 0.09 & 0.38 & 0.68 \\
\hline $\begin{array}{l}\text { Number of places conduct } \\
\text { sex work in district }\end{array}$ & 2 & 9.08 & $0.00^{* *}$ & 1.19 & 0.31 \\
\hline $\begin{array}{l}\text { Number of places conduct } \\
\text { sex work outside district }\end{array}$ & 2 & 3.07 & 0.05 & 0.36 & 0.70 \\
\hline Sources of income & 2 & 0.46 & 0.63 & 0.11 & 0.89 \\
\hline Own a cell phone & 1 & 0.04 & 0.84 & 0.00 & 1.00 \\
\hline $\begin{array}{l}\text { Type of location for sex } \\
\text { work }\end{array}$ & 3 & 2.49 & 0.06 & 0.22 & 0.88 \\
\hline $\begin{array}{l}\text { First sex work experience } \\
\text { was coerced }\end{array}$ & 1 & 1.13 & 0.29 & 0.99 & 0.32 \\
\hline Know someone with HIV & 1 & 0.02 & 0.89 & 0.21 & 0.65 \\
\hline Currently in debt & 1 & 18.36 & $0.00 * *$ & 0.58 & 0.45 \\
\hline Has children & 1 & 2.34 & 0.13 & 1.00 & 0.32 \\
\hline Has school-aged children & 1 & 3.51 & 0.06 & 1.47 & 0.23 \\
\hline
\end{tabular}

$* p<0.05, * * p<0.01$

and mental health) were tested as mediators of community mobilization strength for each outcome. Second, the collectivization variables (scales for collective identity, collective efficacy, collective agency, collective action, and social cohesion) were examined as mediators. Lastly, the significant mediators identified during the first two steps were retained in a combined model in order to estimate a final model for each outcome (see Fig. 2).

This reduced set of identification and collectivization scales was then used to estimate the final models for levels of consistent condom use and perceived discrimination among clusters. Our multilevel path analysis (MSEM with observed rather than latent variables) assumed fixed slopes and random intercepts across the clusters. Mplus version 6.12 [32] was employed to analyze these data, which enabled the simultaneous estimation of parameters for a 


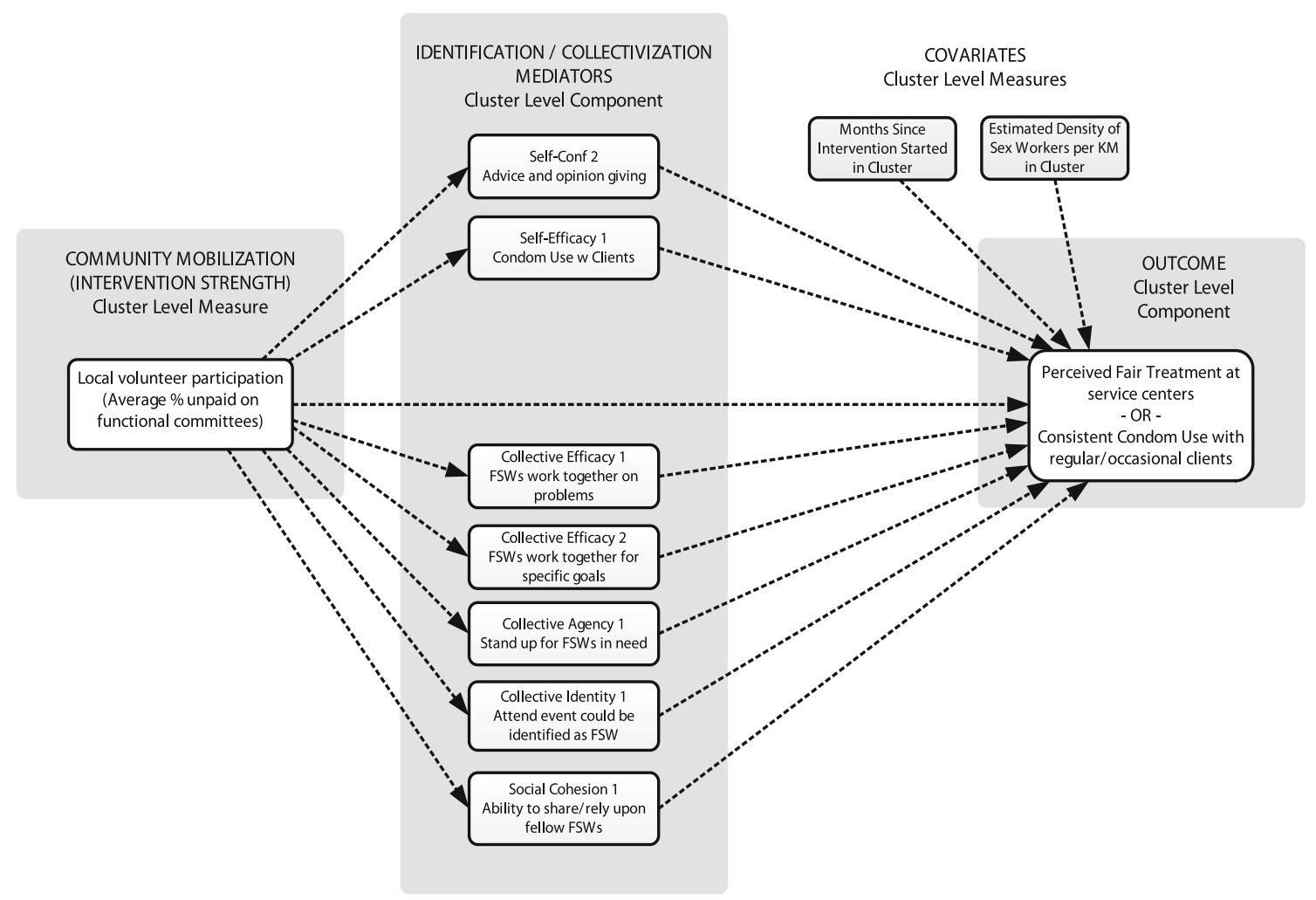

Fig. 2 Estimated path model (cluster level). All mediators were allowed to correlate freely in the model; these curved paths are not illustrated for clarity

weighted two-level analysis with cluster-level mediation [33].

\section{Results}

Of the 1,986 FSWs who participated, over half were currently married $(57 \%)$ and most had children (81\%). Despite most participants having a source of income in addition to their sex work (78 \%), a large majority were in debt $(85 \%)$. Over half worked in an urban environment (53\%). With regards to stability of work environment, approximately two-thirds never traveled for work (61\%) and only conducted sex work in the district in which they were interviewed (71\%). A large majority of participants also personally knew someone living with HIV (84\%). Table 3 provides additional information on background characteristics of the participating individuals.

Even though a single SLP led implementation in all clusters, strength of community mobilization varied considerably across clusters. The rate of participation by volunteer FSWs on program committees within the cluster (strength of community mobilization) ranged from 17 to $73 \%$, with an average of $45 \%$ across the clusters.

Overall, our scales measuring the identification and collectivization mediators had good reliability (see
Table 1) and indicate a sense of identification and collectivization among the population. In the full, unweighted sample, FSWs were generally willing to self-identify as a sex worker-78.5\% strongly agreed or agreed that they were not ashamed to say they are a sex worker in meetings with other sex workers and $79.1 \%$ strongly agreed or agreed that they were not ashamed to tell a social worker or health worker in their community that they are a sex worker. The women reported strong self-efficacy for their ability to use condoms with clients but slightly less confidence in their ability to utilize reproductive health services. Over $60 \%$ felt very or completely confident that they could use condoms even when a client gets angry $(61.4 \%)$ or when a client offers more for sex without a condom $(64.1 \%)$, while only $55.4 \%$ felt very or completely confident in their ability to use condoms with clients if they themselves had been using alcohol or drugs. Only $45.7 \%$ felt very or completely confident in their ability to go to a government health clinic for reproductive health services if they thought the health workers would treat them poorly, and only $41.9 \%$ felt very or completely confident in their ability to do so if the health workers knew they were a sex worker.

The women reported a sense of autonomy in making personal decisions. They did not need permission from someone else for going to a movie (66.5\%), purchasing 
Table 3 Demographic characteristics of survey sample, weighted $(n=1,986)$

\begin{tabular}{lr}
\hline Continuous & Mean (SE) \\
\hline Age in years & $29.19(0.18)$ \\
Age at first sex & $24.79(0.18)$ \\
Years in sex work & $4.11(0.12)$ \\
Years of education (illiterate $=-1)$ & $3.40(0.19)$ \\
\hline Categorical & $\%(\mathrm{SE})$ \\
\hline
\end{tabular}

Marital status

Never married

$9.16(1.15)$

Currently married

$57.08(2.16)$

Deserted/separated/divorced

Widowed

$19.93(1.30)$

$13.83(1.27)$

Current living situation

Living alone

Living with spouse

$4.06(1.30)$

$43.11(2.04)$

Living with $\mathrm{M} / \mathrm{F}$ partner/friend/colleague/other FSW

Living with family

$10.50(1.19)$

$32.33(1.87)$

Environment for sex work

Urban

$53.23(3.04)$

Semi-urban

Rural

$21.86(2.85)$

$24.91(3.16)$

Frequency of travel for sex work

Does not travel

$60.93(2.48)$

A few times per year

Monthly or more

$16.17(1.87)$

$22.90(2.56)$

Number of places conduct sex work in district

Missing/none

$62.02(2.53)$

$1-2$

$3+$

$31.39(2.62)$

Number of places conduct sex work outside district

Missing/none

$70.93(2.27)$

$1-2$

$3+$

$20.69(1.97)$

$8.38(1.22)$

Sources of income

Only sex work

Sex work plus day laborer

Sex work plus domestic help/sell veg or

flowers/student/bar/salon/other

Own a cell phone

No

$79.41(2.18)$

Yes

$20.59(2.18)$

Type of location for sex work

Brothel/bar/hotel/dhaba/highway
Table 3 continued

\begin{tabular}{lr}
\hline Categorical & \multicolumn{1}{c}{$\%(\mathrm{SE})$} \\
\hline Street & $44.99(2.46)$ \\
Home & $9.95(1.53)$ \\
Phone solicitation/other & $37.38(2.65)$
\end{tabular}

First sex work experience was coerced

No

$87.75(1.45)$

Yes

$12.25(1.45)$

Know someone with HIV

No

$16.45(2.23)$

Yes

$83.55(2.23)$

Currently in debt

No

$14.71(1.65)$

Yes

$85.29(1.65)$

Have children

No

$18.68(1.41)$

Yes

$81.32(1.41)$

Have school-aged children

No

$28.40(2.08)$

Yes

$71.60(2.08)$

new clothes $(72.0 \%)$ or participating in NGO activities $(82.5 \%)$. Likewise, they did not need permission to use contraception $(68.0 \%)$ or go to the doctor $(69.4 \%)$. Only $18.7 \%$ reported usually or always turning away clients when tired, however. Just over a quarter reported feeling down, depressed or hopeless more than half the days over the past 2 weeks $(26.9 \%)$.

On the whole, FSWs reported a strong sense of collectivization amongst themselves. Over half the women attended a public event over the past 6 months in which they could be identified as a sex worker (55.7\%). In a 12-item measure of social cohesion on a 4-point scale from strongly disagree to strongly agree, women generally felt they could share with and rely on fellow sex workers for support $(m=2.96)$. Nearly half of the women $(46.8 \%)$ also reported that most or all FSWs would work together to address a problem that affected some or all the group. Over half felt very or completely confident that FSWs would work together to keep each other safe from harm (58.5\%), increase condom use with clients $(81.8 \%)$, speak up for their rights $(70.6 \%)$, and improve their lives $(65.6 \%)$. Furthermore, nearly half reported negotiating with or standing up to a police officer $(42.6 \%)$ or a madam or broker $(42.6 \%)$ during the past 6 months in order to help a fellow sex worker. Fewer women reported actually coming 
together, however, to demand access to entitlements such as voter ID cards $(13.2 \%)$, ration cards $(14.2 \%)$, or health insurance $(17.3 \%)$.

\section{Consistent Condom Use}

Consistency of condom use with clients (occasional and regular) was operationalized as a three-category ordinal variable from low to high. Sixty-one percent of the propensity weighted sample reported high consistency of condom use, meaning they used condoms at every sex act with both regular and occasional clients. Condom use consistency had an intraclass correlation (ICC) of 0.18 , indicating about $18 \%$ of the variance occurred at the cluster level. This degree of cluster-level variation is consistent with other community and school intervention studies, which commonly have ICCs in the $0.05-0.20$ range [34-36].

For our model, the two cluster-level covariates (duration of the Avahan program and density of FSWs in each cluster) were constrained to be independent of the clusterlevel predictor and mediator components. Mediator components were freed to correlate at both the between- and within-cluster level. Tested models were thus nearly saturated, producing a close fit to the data as would be expected (Tucker-Lewis index $=1.00$, RMSEA $=0.002$, $\left.\mathrm{SRMR}_{\text {within }}=0.00, \mathrm{SRMR}_{\text {between }}=0.00\right)$.

Strength of community mobilization was positively associated with psychosocial mediators of identification and collectivization at the cluster level, including: increased self-confidence for advice/opinion giving (b $=0.76, \quad \mathrm{SE}=0.39, \quad \beta=0.23, \quad p<0.05)$, increased collective identity $(\mathrm{b}=1.11, \quad \mathrm{SE}=0.45, \quad \beta=0.40$, $p<0.05$ ), increased collective efficacy for working toward specific goals $(b=1.35, \mathrm{SE}=0.43, \beta=0.35, p<0.01)$, and increased social cohesion $(b=0.57, \quad \mathrm{SE}=0.15$, $\beta=0.36, p<0.01)$. Social cohesion was positively related to increased rates of consistent condom use with clients at the cluster level $(b=2.85, \mathrm{SE}=0.97, \quad \beta=0.85$, $p<0.01)$. There was a significant indirect effect of community mobilization on consistent condom use mediated through social cohesion $(b=1.63, \mathrm{SE}=0.75, \beta=0.31$, $p<0.05$ ); yet the relatively high standard error for the path from social cohesion to consistent condom use would suggest that this link be interpreted cautiously (Fig. 3). None of the other hypothesized mediators were significant, and no direct effect of community mobilization strength on the degree of consistent condom use was found.

\section{Perceived Discrimination}

Perceived discrimination was reverse coded, and renamed perceived fairness. It was operationalized as a 4-item composite variable (Cronbach's $\alpha=0.80$ ) on a 4-point scale representing perceptions of being treated not at all fairly to completely fairly in public places. Perceived fairness had an ICC of 0.37 , indicating that about $37 \%$ of the variance in perceived fairness occurred at the cluster level. The model again had a close fit to the observed data given the unconstrained correlations among mediator components (Tucker-Lewis index $=1.00, \quad$ RMSEA $=$ $\left.0.001, \mathrm{SRMR}_{\text {within }}=0.00, \mathrm{SRMR}_{\text {between }}=0.00\right)$.

As in the model for condom use, strength of community mobilization was positively associated with self-confidence for advice giving $(b=0.76, \quad S E=0.39, \quad \beta=0.23$, $p<0.05), \quad$ collective identity $\quad(\mathrm{b}=1.11, \quad \mathrm{SE}=0.45$, $\beta=0.40, \quad p<0.05)$, and social cohesion $(b=0.57$, $\mathrm{SE}=0.15, \beta=0.36, p<0.01$ ) (Fig. 4).

Strength of community mobilization also had a positive effect on collective efficacy $(b=1.35, \mathrm{SE}=0.43, \beta=0.35$, $p<0.01)$ which was itself related to levels of perceived fairness $(\mathrm{b}=0.86, \mathrm{SE}=0.15, \beta=0.77, p<0.01)$. This yielded a significant mediated effect of community mobilization on perceived fairness through collective efficacy $(\mathrm{b}=1.16, \mathrm{SE}=0.43, \beta=0.27, p<0.01)$. None of the other psychosocial variables mediated the relationship between community mobilization and perceived fairness.

\section{Discussion}

Community mobilization is a component of many HIV prevention programs, and yet little research has been done to evaluate whether or not it significantly contributes to improved outcomes, and, if so, what the mechanisms of effect are. In this study, we demonstrate the added value of community mobilization on key outcomes in an HIV prevention intervention for FSWs. All clusters received the same core intervention activities, yet the level of community mobilization varied widely across clusters, and clusters with stronger community mobilization had more positive HIV prevention outcomes. Not only do we show improved outcomes in geographic clusters with a higher level of community mobilization, but we begin to untangle the mechanism of effect, i.e. how the intervention works through key psychosocial factors of identification and collectivization that are influenced by mobilization.

We used a number of psychosocial scales to measure the processes of identification and collectivization within the FSW population. Many of our scales showed good reliability in this population, including those for self-efficacy, individual agency, social cohesion, mental health, collective efficacy, collective agency and collective action.

To our knowledge, this is the first time the previously validated 2-item depression screener [27] has been used with this population, and it showed strong reliability in our 


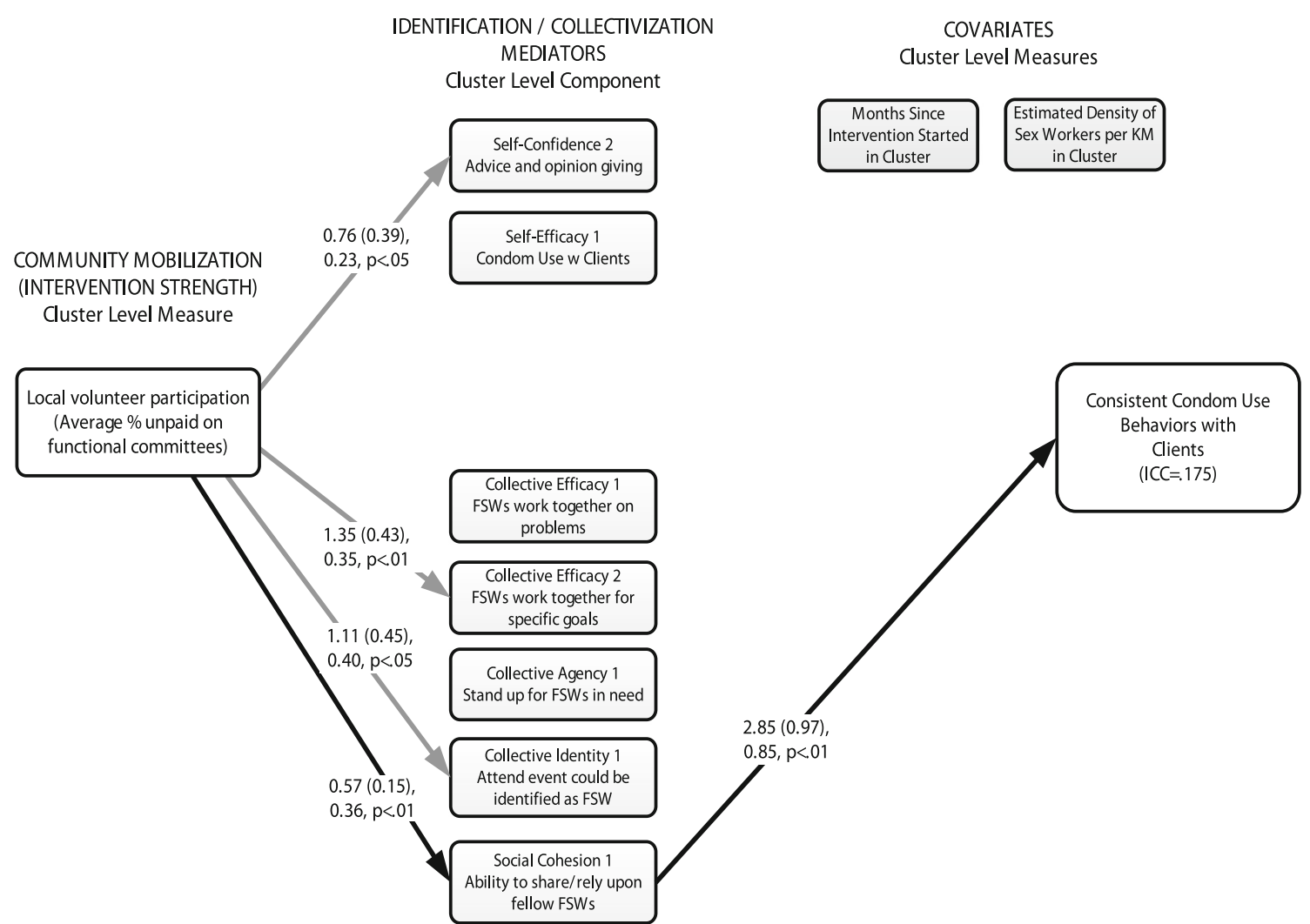

Fig. 3 Cluster-level path model results for condom use with clients. Only significant paths shown; mediators were allowed to correlate freely in the model; curved paths are not shown for clarity. Regression estimates are reported as: unstandardized regression

sample (Cronbach's $\alpha=0.88$ ). Interestingly, the FSWs in our study reported relatively low levels of depression ( $m=2.98$ reverse coded, range 1.0-4.0), compared to a recent study from Goa, India in which $19 \%$ of FSWs surveyed reported attempting suicide within the past 3 months [37]. Although our results cannot confirm this, we believe that community mobilization may provide some protective effects on mental health among FSWs, specifically through increasing social cohesion. The social cohesion scale we adapted [26] showed slightly lower reliability in our sample (Cronbach's $\alpha=0.69$ ) than in the original Lippman study (Cronbach's $\alpha=0.81$ ); however the FSWs from Andhra Pradesh, India in our study reported higher levels of social cohesion $(m=2.96)$ than did FSWs in urban Brazil $(m=1.55){ }^{2}$ This higher level of reported social cohesion may reflect the success of the Avahan community mobilization intervention in building a sense of trust, belongingness, and reciprocity among FSWs.

In both our models of consistent condom use and of perceived fair treatment in public places, the mediation

\footnotetext{
${ }^{2}$ Calculated from reported mean sum divided by reported number of items.
}

coefficient (standard error), standardized regression coefficient, $p$-level. Solid paths indicate significant effects $(p<0.05)$. Darker solid paths represent significant mediated (indirect) effect

effects that were observed both occurred through collectivization type variables: greater social cohesion was associated with increased consistency of condom use, and increased collective efficacy was associated with higher levels of reporting being treated fairly in public places. Our models suggest that these variables may be an important part of the mechanism through which community mobilization produces added value to intervention outcomes. Further disentangling the mechanisms by which community mobilization works to enhance outcomes is vital to improving HIV prevention programming.

Our study is the first to develop an independent measure of community mobilization strength in order to test the relationship between community mobilization and HIV prevention outcomes, including individual perceptions of discrimination in various public settings and consistent condom use with clients. We created a measure of community mobilization - ratio of volunteer FSW participation on program committees-that we believe indicates a deeper level of engagement with and investment in the intervention than simply numbers of participants in program activities. Despite confining this first phase of our evaluation to a specific region within one state, served by a single 


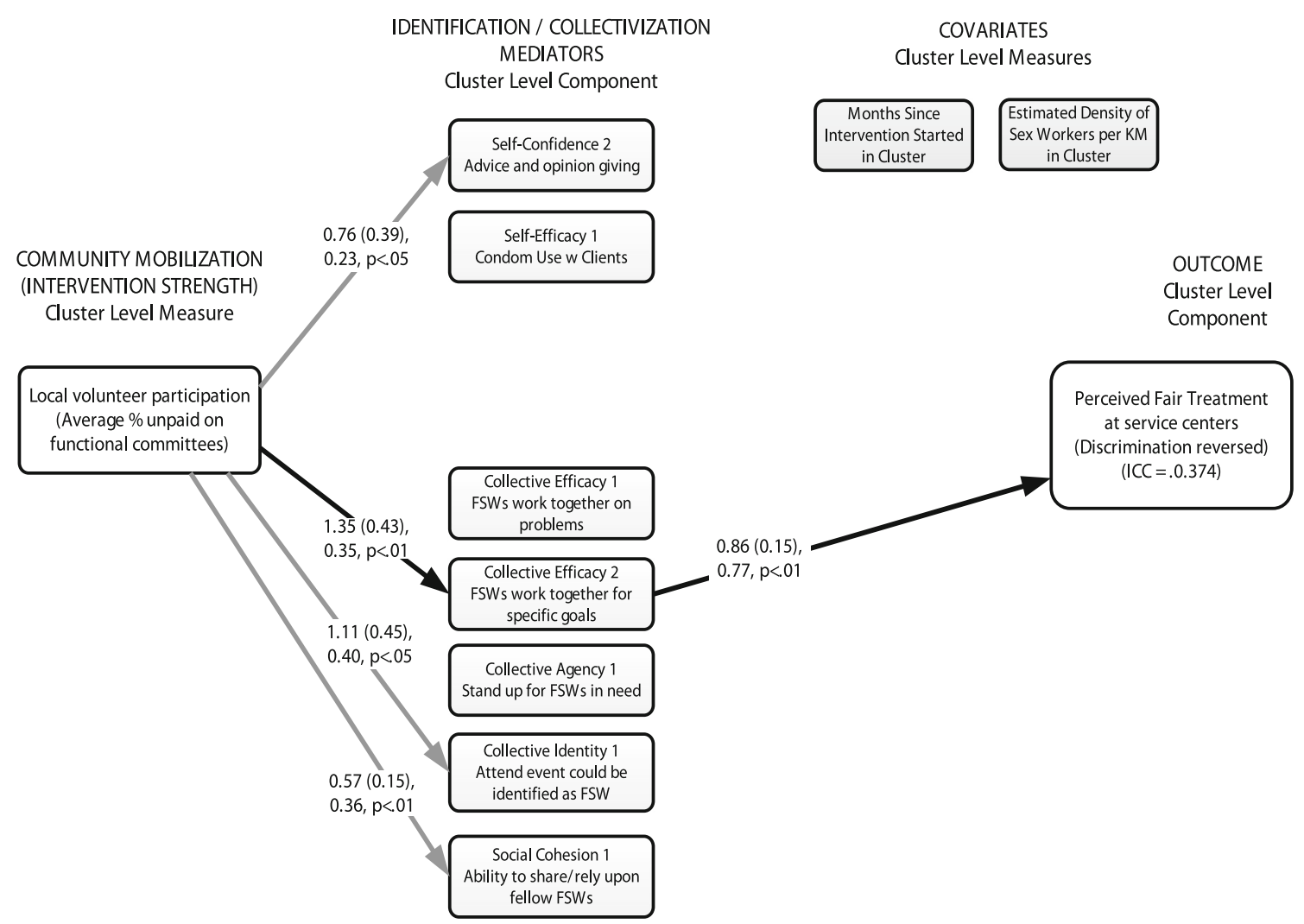

Fig. 4 Cluster-level path model results for perceived fairness. Only significant paths shown; mediators were allowed to correlate freely in the model; curved paths are not shown for clarity. Regression estimates are reported as: unstandardized regression coefficient

implementing partner responsible for the same set of core intervention activities within the clusters, the level of community mobilization varied widely.

Using an independent measure of community mobilization strength and adjusting for potential bias due to nonrandom distribution of participants into clusters with varying levels of treatment, model results suggest that Avahan's community mobilization intervention does have positive indirect effects on FSW rates of consistent condom use and perceived discrimination above and beyond what would be expected due to the core interventions. The effects of community mobilization appear stronger for the enabling environment outcome of perceived discrimination, a social environmental characteristic, than for consistent condom use, an individual-level behavior. Since $37 \%$ of the variance in perceived discrimination exists at the cluster-level versus only seventeen percent for consistent condom use, there was less variance in consistent condom use available at the cluster level to be explained by our model.

Given the intensity of Avahan's targeted intervention activities, including community outreach and condom distribution, it is reasonable to expect that those (standard error), standardized regression coefficient, $p$-level. Solid paths indicate significant effects $(p<0.05)$. Darker solid paths represent significant mediated (indirect) effects

interventions (outreach and condom distribution) would have a more profound effect on condom use than would high levels of engaged participation in the program (i.e. community mobilization). Still, community mobilization aims to help FSWs become more able to make decisions, influence their environment, and shape their lives in health enhancing ways, so we would expect some effect on condom use. The mediating influence of social cohesion on condom use appears to represent that effect, suggesting that a greater sense of belonging, trust and reciprocity among sex workers supports the use of condoms.

As predicted in our model, mediation effects occurred through the collectivization variables of social cohesion and collective efficacy for working together towards common goals, suggesting an important role for these constructs in producing positive program effects. The importance of collectivization is consistent with other studies of Avahan that show collective identity, efficacy, and agency associated with consistent condom use [21, 23, 38].

Still, our model of how community mobilization works to produce better outcomes is only partially validated. We predicted that community mobilization would catalyze a 
process of identification as a sex worker and increase selfefficacy and agency. Although the intervention was positively associated with these identification variables, they did not mediate the relationship between strength of community mobilization and consistent condom use or perceived discrimination. This suggests that change in the degree of identification may be necessary to change collectivization but not sufficient alone for influencing positive outcomes at the cluster level. Interestingly, while strength of the community mobilization intervention was positively related to collective identity, collective efficacy, and social cohesion, there was no significant relationship between strength of the intervention and measures of taking action on behalf of one another-collective agency and collective action. Perhaps these effects will emerge over time.

Our findings suggest that community mobilization may contribute to the success of Avahan by increasing the degree of social cohesion among FSWs which in turn increases rates of consistent condom use with clients. Community mobilization is also positively associated with levels of collective efficacy among FSWs, which in turn is associated with increased perceptions of fair treatment in public places such as banks, hospitals, and post offices.

\section{Limitations}

Drawing from our program theory, we conducted a crosssectional evaluation of model constructs for which we were able to construct valid measures. Not all of our measures fully captured the constructs of interest, however. For example, our measure of strength of community mobilization assessed level of volunteer participation of the FSWs in program committees as an indication of FSWs participation, engagement, commitment and ownership of the program-key characteristics of a "mobilized community". Other measures of mobilization, such as the length and type of participation in the program (e.g. as an office holder), frequency of participation, and success of the various program committees in effecting change in the community, are not captured by our measure. Finally, though we weighted the sample to account for the timelocation sampling procedures and the inverse propensity score weighting adjusted for bias associated with the 18 variables we identified, we cannot adjust for potential bias from unmeasured sources.

\section{Future Directions}

Much has been written about Avahan recently. A populationlevel assessment estimated that Avahan averted over
$100,000 \mathrm{HIV}$ infections in India from 2003 to 2008 [39], and a more recent study suggests that infections averted are linked to large increases in condom use since implementation of Avahan [40]. Other studies have found associations between self-reported program exposure to Avahan and condom use within a single district in Andhra Pradesh, India $[21,22,41]$. We took a new approach to evaluating the program by focusing on the added value of community mobilization, as measured independently at the cluster-level.

Because community mobilization is both time and resource intensive, we believe it is important that programs explicitly evaluate the value added, even though this is difficult. Many believe that community mobilization improves program outcomes and long-term sustainability of those outcomes, but an evidence-base to support these assumptions must be established. As one part of building this evidence-base, our model of the relationship between community mobilization strength and HIV prevention outcomes should be validated across other SLPs in Avahan and across the different target populations of the program.

To better understand the mechanisms by which community mobilization enhances health outcomes (not just HIV prevention) and which intervention components are most essential for, and efficient at, spurring community mobilization, future interventions should plan carefully for the evaluation of the community mobilization process and outcomes, including the collection of baseline and nonintervention area data. Furthermore, more robust measures of community mobilization need to be developed. Measures of empowerment that include changes in relationship dynamics between community members and power holders, and more nuanced measures of participation and confidence in ability to influence power holders, would all enhance our understanding of how community mobilization works. We look forward to future investigations in these areas.

Acknowledgments We would like to thank Gina Dallabetta and Tisha Wheeler for their insights into the conceptual framework and their assistance in clarifying the hypotheses and defining the variables. The work of Philip Hastings was supported by a contract (\#18595) from the Bill and Melinda Gates Foundation.

Open Access This article is distributed under the terms of the Creative Commons Attribution License which permits any use, distribution, and reproduction in any medium, provided the original author(s) and the source are credited.

\section{References}

1. Ghys PD, Diallo MO, Ettiéngne-Traoré V, et al. Effect of intervention to control sexually transmitted disease on the incidence of HIV infection in female sex workers. AIDS. 2001;15:1421-31.

2. Ford K, Wirawan DN, Reed BD, Muliawan P, Wolfe R. The Bali STD/AIDS study: evaluation of an intervention for sex workers. Sex Trans Dis. 2002;29(1):50-8. 
3. Rou K, Wu Z, Sullivan SG, et al. A five-city trial of a behavioural intervention to reduce sexually transmitted disease/HIV risk among sex workers in China. AIDS. 2007;21(suppl 8):S95-101.

4. Galavotti C, Wheeler T, Kuhlmann AS, et al. Navigating the swampy lowland: a framework for evaluating the effect of community mobilization in female sex workers in Avahan, the India AIDS initiative. $\mathrm{J}$ Epidemiol Community Health. 2012;66(Suppl 2):ii9-15.

5. Basu I, Jana S, Rotheram-Borus MJ, et al. HIV prevention interventions among sex workers in India. JAIDS. 2004;36(3): $845-52$.

6. Gutierrez JP, McPherson S, Fakoya A, Matheou A, Bertozzi SM. Community-based prevention leads to an increase in condom use and a reduction in sexually transmitted infections (STIs) among men who have sex with men (MSM) and female sex workers (FSW): the Frontiers Prevention Project (FPP) evaluation results. BMC Public Health. 2010;10:497.

7. Morisky DE, Ang A, Coly A, Tiglao TV. A model HIV/AIDS risk reduction programme in the Philippines: a comprehensive community-based approach through participatory action research. Health Promot Int. 2004;19(1):69-76.

8. Smith L, Kahn F, Frankenberger T, Wadud A. Admissible evidence in the court of development evaluation? The impact of CARE's SHOUHARDO Project on child stunting in Bangladesh. IDS Working Paper 376, Institute of Development Studies; 2011.

9. Manandhar DS, Osrin D, Shrestha BP, et al. Effect of a participatory intervention with women's groups on birth outcomes in Nepal: cluster-randomised controlled trial. Lancet. 2004;364: 970-9.

10. Tripathy $\mathrm{P}$, Nair N, Barnett $\mathrm{S}$, et al. Effect of a participatory intervention with women's groups on birth outcomes and maternal depression in Jharkhand and Orissa, India: a cluster-randomised controlled trial. Lancet. 2010;375(9721): 1182-92.

11. The Health Foundation. Improving maternal and newborn health in Malawi: lessons from a landmark programme addressing maternal and newborn health in Malawi. London: The Health Foundation; 2012.

12. Hossain J, Ross SR. The effect of addressing demand for as well as supply of emergency obstetric care in Dinajpur, Bangladesh. Int J Gynaecol Obstet. 2006;92(3):320-8.

13. Avahan. Avahan-the India AIDS initiative: the business of HIV prevention at scale. New Delhi: Bill \& Melinda Gates Foundation; 2008.

14. Chandrasekaran P, Dallabetta G, Loo V, et al. Evaluation design for large-scale HIV prevention programmes: the case of Avahan, the India AIDS Initiative. AIDS. 2008;22:S1-15.

15. Steen R, Mogasale V, Wi T, et al. Pursuing scale and quality in STI interventions with sex workers: initial results from Avahan India AIDS Initiative. Sex Transm Infect. 2006;82:381-5.

16. Verma R, Shekhar A, Khobragade S, et al. Scale-up and coverage of Avahan: a large scale HIV-prevention programme among female sex workers and men who have sex with men in four Indian states. Sex Transm Infect. 2010;86:i76-82.

17. Wheeler T, Kiran U, Dallabetta G, et al. Learning about scale, measurement and community mobilisation: reflections on the implementation of the Avahan HIV/AIDS initiative in India. J Epidemiol Community Health. 2012;66(Suppl 2):ii16-25.

18. White H. Theory-based impact evaluation: principles and practice. International Initiative for Impact Evaluation. Working Paper 3; New Dehli; 2009.

19. Gamson WA. The social psychology of collective action. In: Morris AD, Mueller CM, editors. Frontiers in social movement theory. New Haven: Yale University Press; 1992.

20. Taylor V, Whittier NE. Collective identity in social movement communities: lesbian feminist mobilization. In: Morris AD,
Mueller CM, editors. Frontiers in social movement theory. New Haven: Yale University Press; 1992.

21. Blankenship KM, West B, Kershaw T, Biradavolu MR. Power, community mobilization, and condom use practices among female sex workers in Andhra Pradesh. India. AIDS. 2008;22: S109-16.

22. Reza-Paul S, Beattie T, Syed HU, et al. Declines in risk behaviour and sexually transmitted infection prevalence following a community-led HIV preventive intervention among female sex workers in Mysore, India. AIDS. 2008;22:S91-100.

23. Beattie T, Bhattacharjee $\mathrm{P}$, Chandrashekar S, et al. Community mobilisation and empowerment of female sex workers is significantly associated with reduced HIV/STI risk in Karnataka state, south India. Poster presented at the International AIDS Conference; Washington, DC; 2012.

24. Thomas T, Narayanan P, Wheeler T, Kiran U, Joseph MJ, Ramanathan TV. Design of a community ownership and preparedness index: using data to inform community capacity development. J Epidemiol Community Health. 2012;66(Suppl 2):ii26-33.

25. Punyam S, Pullikalu RS, Mishra RM, et al. Community advocacy groups as a means to address the social environment of female sex workers: a case study in Andhra Pradesh, India. J Epidemiol Community Health. 2012;66(Suppl 2):ii87-94.

26. Lippman SA, Donini A, Díaz J, Chinaglia M, Reingold A, Kerrigan D. Social-environmental factors and protective sexual behavior among sex workers: the Encontros intervention in Brazil. Am J Public Health. 2009;99:S216-23.

27. Kroenke K, Spitzer RL, Williams JB. The patient health questionnaire-2: validity of a two-item depression screener. Med Care. 2003;41:1284-92.

28. D'Agostino RB. Propensity score methods for bias reduction in the comparison of a treatment to a non-randomized control group. Stat Med. 1998;17:2265-81.

29. Imbens GW. The role of the propensity score in estimating doseresponse functions. Biometrika. 2000;87(3):706-10.

30. Yanovitzky I, Zanutto E, Hornik R. Estimating causal effects of public health education campaigns using propensity score methodology. Eval Program Plan. 2005;28:209-20.

31. Crump RK, Hotz JV, Imbens GW, Mitnik OA. Dealing with limited overlap in estimation of average treatment effects. Biometrika. 2009;96(1):187-99.

32. Muthén LK, Muthén, BO. Mplus user's guide: statistical analysis with latent variables. 6th ed. Los Angeles; 1998-2010.

33. Preacher KJ, Zyphur MJ, Zhang Z. A general multilevel SEM framework for assessing multilevel mediation. Psychol Methods. 2010;15:209-33.

34. Preacher KJ, Zhang Z, Zyphur MJ. Alternative methods for assessing mediation in multilevel data: the advantages of multilevel SEM. Struct Equ Model. 2011;18:161-82.

35. Hox J. Multilevel analysis: techniques and applications. Mahwah: Lawrence Erlbaum Associates, Inc.; 2002.

36. Gulliford MC, Ukoumunne OC, Chinn S. Components of variance and intraclass correlations for the design of communitybased surveys and intervention studies: data from the health survey for England 1994. Am J Epidemiol. 1999;149(9):876-83.

37. Shahmanesh M, Wayar S, Cowan F, Mabey D, Copas A, Patel V. Suicidal behavior among female sex workers in Goa, India: the silent epidemic. Am J Public Health. 2009;99:1239-46.

38. Gaikwad SS, Bhende A, Nidhi G, Saggurti N, Ranebennur V. How effective is community mobilization in HIV prevention among highly diverse sex workers in urban settings? The Aastha intervention experience in Mumbai and Thane districts, India. J Epidemiol Community Health. 2012;66(Suppl 2):ii69-77.

39. Ng M, Gakidou E, Levin-Rector A, Khera A, Murray CJ, Dandona L. Assessment of a population-level effect of Avahan, an HIV prevention initiative in India. Lancet. 2011;378:1643-52. 
40. Pickles M, Boily MC, Vickerman P, et al. Assessment of the population-level effectiveness of the Avahan HIV-prevention programme in South India: a preplanned, causal-pathway-based modelling analysis. The Lancet. 2013. doi:10.1016/S2214109X(13)70083-4.
41. Erausquin JT, Biradavolu M, Reed E, Burroway R, Blankenship KM. Trends in condom use among female sex workers in Andhra Pradesh, India: the impact of a community mobilization intervention. J Epidemiol Community Health. 2012;66(Suppl 2): ii49-54. 